\title{
Eastern spread of the invasive Artemia franciscana in the Mediterranean Basin, with the first
}

record from the Balkan Peninsula

Zsófia Horváth ${ }^{1,2^{*}}$, Christophe Lejeusne ${ }^{3,4}$, Francisco Amat ${ }^{5}$, Javier Sánchez-Fontenla ${ }^{3}$, Csaba F. Vad ${ }^{1}$, Andy J. Green ${ }^{3}$

${ }^{1}$ WasserCluster Lunz, Dr. Carl Kupelwieser Promenade 5, 3293 Lunz am See, Austria

${ }^{2}$ German Centre for Integrative Biodiversity Research (iDiv), Halle-Jena-Leipzig, Germany

${ }^{3}$ Doñana Biological Station EBD-CSIC, Avda. Américo Vespucio 26, 41092 Sevilla, Spain

${ }^{4}$ Sorbonne Université (UPMC Paris 06), CNRS, Station Biologique de Roscoff, UMR 7144 AD2M,

Place Georges Teissier CS90074, 29688 Roscoff, France

${ }^{5}$ Instituto de Acuicultura de Torre de la Sal (CSIC), 12595 Ribera de Cabanes (Castellon), Spain

* corresponding author: hhzsofia@gmail.com

\begin{abstract}
In the last 30 years since its first appearance in Portugal, the North-American Artemia franciscana has successfully invaded hypersaline habitats in several Mediterranean countries. Here, we review its spread in the Mediterranean Basin since its first occurrence in the 1980s and report its first occurrence in Croatia, based on both morphological identification (adults) and genetic evidence (cysts). The haplotypes we found in the population from this new locality (two of which were new to both the native and invaded ranges of $A$. franciscana) suggest either direct or secondary introduction from the main harvested cyst sources (Great Salt Lake or San Francisco Bay, USA) and indicate that some genetic native diversity in the species has not yet been captured by existing studies. Our finding means that the species has reached the eastern shores of the Adriatic Sea and therefore is now present on the Balkan Peninsula. We detected that its eastward spread is still continuing, posing a fundamental threat to remaining populations of native Artemia species in Eastern Europe.
\end{abstract}

\section{Keywords}

invasive species, Artemia franciscana, salt works, Mediterranean 


\section{Introduction}

The Nearctic-Neotropical brine shrimp Artemia franciscana has invaded several other parts of the world in the last decades. In the Mediterranean Basin, its spread is relatively well-documented. Since its first finding in the 1980s in Portugal, it has reached Morocco and Tunisia in North-Africa and several European countries along the western shores of the Mediterranean Sea, even spreading northwards along the Atlantic coast of France (Fig. 1a; Amat et al., 2005; Mura et al., 2006; Muñoz, 2009; Ben Naceur et al., 2010; Scalone \& Rabet, 2013). The arrival of A. franciscana in a new habitat has drastic consequences for the native communities. Since it is a better competitor than its native European counterparts, A. salina and A. parthenogenetica (Browne \& Halanych, 1989), it rapidly displaces them (Amat et al., 2005, 2007), leading to the loss of genetically-unique populations (Muñoz et al., 2008). Its displacement of native Artemia is largely due to its higher reproductive rate (Amat et al., 2007) and can be further fostered by the higher prevalence of avian cestode parasites in the native species (Redón et al., 2015). A. franciscana is furthermore a more efficient filter-feeder than the native species, and hence its replacement of native Artemia might influence the entire food web by increasing grazing pressure on phytoplankton communities (Sánchez et al., 2016). Therefore, its spread represents a threat to the central and eastern Mediterranean region, where hypersaline habitats are still inhabited by the native species (Mura et al., 2006; Fig 1b).

A. franciscana cysts are commercially available worldwide almost everywhere, originating (directly or indirectly) mainly from two locations in the USA: San Francisco Bay (SFB) and Great Salt Lake (GSL). According to a recent genetic study (Muñoz et al., 2014), it is most likely that its current Mediterranean distribution is a result of multiple (human) introductions of strains from SFB and GSL, but in some cases, natural dispersal by waterbirds could have also occurred from already established populations (Green et al., 2005).

In this study, we present the first appearance of $A$. franciscana in Croatia, compare haplotypes with other Mediterranean and commercially used populations, and review the current distribution of the species in the Mediterranean Basin, demonstrating its further eastward invasion 


\section{Materials and methods}

Artemia samples were collected from the Nin salt works in Croatia in August 2011. The Nin salt works (Solana Nin, N 44.24254, E 15.192166, Fig. 1) are one of the oldest and still operational salinas on the Adriatic seashore of Croatia. They are located in the Nin bay, on the northernmost part of the Zadar peninsula, in the centre of Dalmatia, and cover 55 ha. They are so-called solar salt works, where only solar energy is used for the concentration of salt in the evaporation pans. We found Artemia populations in two neighbouring pans. One of them had deeper water and much higher Artemia densities (we refer to this one as no. 1, while the other we name no. 2). They had similar conductivity and total phosphorus (TP) values (no. 1: $204 \mathrm{mS} / \mathrm{cm}, \mathrm{TP}: 153.7 \mu \mathrm{g} / \mathrm{l}$; no. 2: $210 \mathrm{mS} / \mathrm{cm}$, $100.3 \mu \mathrm{g} / \mathrm{l})$. TP from water samples was measured spectrophotometrically as molybdate reactive phosphorous after persulphate digestion in the lab (Eaton et al., 2005).

Animals were collected from both pans with a plankton net and were preserved in $70 \%$ ethanol. Free-swimming cysts were also collected and stored in 96\% ethanol. Morphological identification of the first 100 adults was based on Hontoria \& Amat (1992) and Mura \& Brecciaroli (2004).

Genomic DNA was extracted from randomly chosen individual cysts using the HotSHOT protocol (Montero-Pau et al., 2008). The Artemia-specific primers 1/2COI Fol-F and 1/2COI Fol-R (Muñoz et al., 2008) were used to amplify and sequence a fragment of the mitochondrial Cytochrome $c$ Oxidase Subunit I gene (COI). PCRs were performed using the same protocol as in Muñoz et al. (2008). PCR cycling consisted in a first cycle of $3 \mathrm{~min}$ at $94^{\circ} \mathrm{C}$, followed by 35 cycles of $45 \mathrm{~s}$ at $94^{\circ} \mathrm{C}$, $1 \mathrm{~min}$ at $55^{\circ} \mathrm{C}$ and $1 \mathrm{~min}$ at $72^{\circ} \mathrm{C}$, then a final elongation step of $5 \mathrm{~min}$ at $72^{\circ} \mathrm{C}$. PCR products were checked for amplification on a 1\% agarose gel using SYBR Safe DNA gel stain, then directly sequenced by the company Macrogen. A total of 34 individual sequences from Nin (Croatia) were trimmed and aligned using BIOEDIT v7.0.9 (Hall, 1999), and all new haplotypes were deposited in Genbank (Genbank accession numbers: MH197108-MH197111, see also Table S2 in Supplementary Material). Our COI data set was combined with some previously published data sets from Muñoz et al. (2013, 2014) and Eimanifar et al. (2015) (see Table XXX for accession numbers). Basic population statistics for the Nin population were generated using DNAsp (Librado \& Rozas, 2009). A statistical 
parsimony haplotype network (Clement et al., 2000) with a parsimony connection limit of $95 \%$ was generated using Popart (Leigh \& Bryant, 2015).

We also compiled available data on the observation of $A$. franciscana in Mediterranean waters to visualise its spread over the last 30 years (Amat et al., 2005; Mura et al., 2006; Muñoz, 2009; Ben Naceur et al., 2010; Scalone \& Rabet, 2013; Sánchez et al., 2017). If multiple observations were reported from the same location, we used the earliest one as the first year of observation for the given location.

\section{Results}

The two populations of the Nin salt works were both bisexual (females:males ratio was 56:44 in pan no. 1, and 65:35 in pan no. 2), consisting either entirely of adults (pan. no. 2) or with a very few pre-adults (pan no. 1). Based on adult morphology, individuals were all identified as Artemia franciscana. The spherical frontal knob on the head of males was clearly visible. Females had sharply pointed ovisacs, short antennules, and lateral lobules before the ovisacs.

After sequencing and trimming, a COI fragment of 548bp was obtained for 34 cysts sequenced from the Nin salt works. An analysis of local similarity between sequences (BLAST) has unambiguously confirmed the morphological identification of the Nin salt work cysts as $A$. franciscana $($ Blast-n identity $=99 \%$, e-value $=0.0$ ). Overall, 5 variable sites, including 4 parsimony informative sites, were found for the Nin sequences, with no indels or stop codons. No nonsynonymous substitutions were found among the sequences.

We found a total of four haplotypes (hereafter referred as NIN_01, NIN_02, NIN_03 and NIN_14) over 28 sequenced individuals. Two of them were very common in our dataset (43\% and 46\% of cysts for NIN_01 and NIN_02, respectively) while NIN_03 and NIN_14 showed low frequency (4\% and 7\% of cysts, respectively). The haplotype diversity $(h)$ and nucleotide diversity $(\pi)$ were 0.616 and 0.00327 , respectively for the Nin sampling point. The haplotype network (Fig. 2) clearly shows a star-like structuring among four haplotypes (Af49, Af90, NIN_02, Haf04). The two most frequent Nin haplotypes, NIN_01 and NIN_02, were identical for our 548bp COI fragment to haplotypes reported worldwide and originating from the native American range, which includes the 
two commercial SFB and GSL populations and China (Fig. 2 and Table S1 in Supplementary Material). They are also well established in the invaded Mediterranean range (Table S1 in Supplementary Material). The low-frequency Croatian haplotypes NIN_03 and NIN_14 were directly linked to the highly connected and common haplotype NIN_02, but are private (i.e. found only at the sampling location) to the Nin salt works and had never been recorded before (Fig. 2 and Table S1 in Supplementary Material).

\section{Discussion}

For the first time, we have demonstrated the occurrence of Artemia franciscana in Croatia, its easternmost occurrence in the Mediterranean region. Previously, no Artemia species, either native or introduced, have been recorded from the Nin salt works, or in the vicinity of Nin (Petrović, 1991). This suggests that this alien species has colonized a habitat that was unoccupied by native species. In fact, our finding is the first recent Artemia occurrence in Croatia. Although there are data in the literature listed as Croatian (e.g. Triantaphyllidis et al., 1998; Muñoz \& Pacios, 2010), these are errors: the locations reported are Montenegrin (Ulcinj) and Slovenian (Sečovlje, Strunjan; see also Fig. 1b), suggesting incoherent usage of country data and names after the breakdown of former Yugoslavia. These data from today's Slovenia and Montenegro represent the nearest populations of Artemia spp. in the Balkans. The sampling campaign carried out in the 1980s proved them all to be reproducing parthenogenetically, indicated clonal populations typically named as A. parthenogenetica (Petrović, 1991). Since then, we have no information as to whether A. franciscana has colonized these locations. During the years immediately after its initial appearance in Portugal in the 1980s, there were only a few observations of $A$. franciscana in new locations (Fig. 3). Altogether, there are only seven new occurrences before 2000, while most of the reports we have identified (25) are from 2000-2005. This was the period when the species invaded Spain, spread along the coasts of France, and first appeared in Morocco and Italy (Fig. 3). After 2005, there are only five new locations, including our own data (Croatia, 2011), two in Spain $(2007,2016)$, one in France (2007), and the first record in Tunisia (2009). 
The genetic analysis of this newly introduced A. franciscana population in Croatia provides some evidence as to the possible origin and vector of introduction of this species. The four different haplotypes found in the Nin salt work are identical (NIN_01 and NIN_02) or closely related (NIN_03 and NIN_14) to widespread haplotypes all over both the native and introduced range of A. franciscana (Table S1 in Supplementary Material). This suggests an introduction through commercial cysts (mainly used in aquaculture and the aquarium trade) as it has been previously demonstrated for most of the introduced range of A. franciscana (Amat et al., 2005; Muñoz et al., 2013, 2014). Combined with previous results from the literature, our results suggest an introduction from the main harvested cysts sources from the Great Salt Lake (GSL) or San Francisco Bay (SFB), which have been historically the two most commercially distributed native populations (Amat et al., 2005).

On the other hand, as in the population genetics study of Muñoz et al. (2014) on A. franciscana in the western basin of the Mediterranean, we cannot exclude secondary introductions from Asia into locations like the Croatian Nin salt works. SFB and GSL haplotypes (here referred as NIN_01 and NIN_02; see Table S1 in Supplementary Material for more details) have high frequencies in introduced populations of A. franciscana in different Asian countries like China, India and Vietnam (Muñoz et al., 2014). Moreover, A. franciscana cysts from Bohai Bay in China are readily available on the world market (Van Stappen et al., 2007; Muñoz et al., 2014). The introduction of A. franciscana in Croatia may be explained by a direct introduction of commercially available cysts originating from North America or China.

Interestingly, we found two haplotypes (NIN_03 and NIN_14; so far private to Croatia) new to both the native and invaded ranges of A. franciscana, supporting the possibility of a novel introduction from a commercial source. This indicates that continued commercialization of this highly invasive crustacean continues to promote its spread at the expense of native Artemia populations, and that stopping such commercialization is likely to reduce the spread. This finding also suggests the full genetic diversity of $A$. franciscana has not yet been sampled in either its invaded or its native range. High haplotype diversity in alien crustacean populations is not unusual (Lejeusne et al., 2014). It is very likely that in the large and intensively harvested population Great Salt Lake, some genetic native diversity has not yet been captured by existing studies. These private haplotypes are likely to originate 
in the two cited USA populations, but we cannot rule out the possibility that some other native locations (e.g. Muñoz et al., 2013) may have contributed to the invasion process of $A$. franciscana. Further study of the genetic diversity in the native range would help improve the understanding of the invasion history process of this species.

An alternative explanation for the arrival of $A$. franciscana in Croatia is dispersal by migratory waterbirds, which can be efficient dispersers of $A$. franciscana cysts through endozoochory (Green et al., 2005; Sánchez et al., 2012; Muñoz et al., 2013; Reynolds et al., 2015). Even though there are no known A. franciscana localities in the close Balkan neighbourhood, the Italian locality of Margherita di Savoia is only $300 \mathrm{~km}$ from Nin. Although most cysts dispersed by waterbirds will be transported within $100 \mathrm{~km}$, successful dispersal events are also expected over several hundreds of km (Sánchez et al., 2012; Viana et al., 2013). However, our analysis did not show the presence in the Nin salt works (see Table S1 in Supplementary Material and Fig. 2) of any haplotype previously reported from Margherita di Savoia (haplotypes HAf04, HAf07 and Af10; Muñoz et al., 2013, 2014). This suggests there is no direct connection between the Nin population and the geographically closest known population of A. franciscana. However, we cannot rule out the possibility of an introduction via waterbird movement of the American brine shrimp to Nin from some other more remote, or as yet unknown, Mediterranean location. Furthermore, the general pattern of eastward spread of the species in the Mediterranean Basin (Fig. 3) implies an important role for stepwise secondary dispersal events, instead of a series of independent direct human introductions of cysts originating directly from commercial sources. Birds may play a major role in such stepwise spread, although human vectors may also be important (Waterkeyn et al., 2010).

When contemplating merely the frequency of finding A. franciscana in new localities around the Mediterranean Sea, one might conclude that the fastest spread of the species has occurred around year 2000, and that since then it has slowed down somewhat. However, if we consider not only the number of new populations but also their location (Fig. 3), we can detect that the eastward spread is still continuing and that the gaps in the data are more likely to be attributable to a sampling effect. The ongoing eastward spread poses a fundamental threat to the eastern Mediterranean and Black Sea populations of native Artemia species in countries such as Greece, Turkey, Bulgaria or Israel (Muñoz 
\& Pacios, 2010). The arrival of A. franciscana to Croatia increases the chances of its further spread to all nearby salt works in Italy and the Balkan Peninsula that are still known to host native (Fig. 1b) or no Artemia. At the same time, most of these data come from the 1980 s and 90 s, which emphasises that more effort is needed to update our knowledge on the actualcurrent distribution of all Artemia species in the central and eastern Mediterranean. While it is unlikely that the commercialization of $A$. franciscana within the Mediterranean region could be efficiently prevented in order to safeguard remaining native Artemia biodiversity, stricter regulation of aquaculture effluents and aquarium trade might help to slow down the spread of the species, e.g. through regionally adopted legislation that only enables the use of native species in local aquaculture and salt works, preferentially originating from the nearest native population. Harvesting and storing substantial quantities of cysts in gene banks would also be an important conservation effort for preserving the gene pool of native populations still existing in the region. Furthermore, improvement in the communication between conservation authorities and local stakeholders is erucially-vitally important to reduce the risk of direct introduction events of the invasive $A$. franciscana.

\section{Acknowledgements}

The molecular analyses were funded by the Ministerio de Ciencia e Innovación (Proyecto CGL201016028) and the CSIC (PIC2015FR4) in Spain, and CNRS-funded PICS program (PICS07360) in France. The authors thank the staff of Solana Nin for granting access to the sites.

\section{References}

Abatzopoulos, T. J., C. D. Triantaphyllidis, \& C. D. Kastritsis, 1987. Preliminary studies on some Artemia populations from northern Greece. Artemia research and its applications 1: 107-114.

Amat, F., F. Hontoria, J. C. Navarro, N. Vieira, \& G. Mura, 2007. Biodiversity loss in the genus Artemia in the Western Mediterranean Region. Limnetica 26: 387-404.

Amat, F., F. Hontoria, O. Ruiz, A. J. Green, M. I. Sanchez, J. Figuerola, \& F. Hortas, 2005. The American brine shrimp as an exotic invasive species in the western Mediterranean. Biological Invasions 7: 37-47.

Ben Naceur, H., A. B. R. Jenhani, \& M. S. Romdhane, 2010. Biological characterization of the new invasive brine shrimp Artemia franciscana in Tunisia: Sabkhet Halk El-Menzel. Int. J. Biol. And Life Sciences 6: 3 . 
Browne, R. A., \& K. M. Halanych, 1989. Competition between sexual and parthenogenetic Artemia: a re-evaluation (Branchiopoda, Anostraca). Crustaceana 57: 57-71.

Clement, M., D. Posada, \& K. A. Crandall, 2000. TCS: a computer program to estimate gene genealogies. Molecular ecology 9: 1657-1659.

Eaton, A. D., L. S. Clesceri, E. W. Rice, A. E. Greenberg, \& M. A. H. Franson, 2005. Standard methods for the examination of water and wastewater. 2005. Washington, DC: American Public Health Association 21:

Eimanifar, A., B. Marden, M. S. Braun, \& M. Wink, 2015. Analysis of the genetic variability of Artemia franciscana Kellogg, 1906 from the Great Salt Lake (USA) based on mtDNA sequences, ISSR genomic fingerprinting and biometry. Marine Biodiversity 45: 311-319.

Green, A. J., M. I. Sánchez, F. Amat, J. Figuerola, F. Hontoria, O. Ruiz, \& F. Hortas, 2005. Dispersal of invasive and native brine shrimps Artemia (Anostraca) via waterbirds. Limnology and oceanography 50: $737-742$.

Hall, T. A., 1999. BioEdit: a user-friendly biological sequence alignment editor and analysis program for Windows 95/98/NT. Nucleic acids symposium series. : 95-98, http://jwbrown.mbio.ncsu.edu/JWB/papers/1999Hall1.pdf.

Hontoria, F., \& F. Amat, 1992. Morphological characterization of adult Artemia (Crustacea, Branchiopoda) from different geographical origins. American populations. Journal of Plankton Research 14: 1461-1471.

Leigh, J. W., \& D. Bryant, 2015. popart: full-feature software for haplotype network construction. Methods in Ecology and Evolution 6: 1110-1116.

Lejeusne, C., A. Saunier, N. Petit, M. Béguer, M. Otani, J. T. Carlton, C. Rico, \& A. J. Green, 2014. High genetic diversity and absence of founder effects in a worldwide aquatic invader. Scientific reports 4: 5808 .

Librado, P., \& J. Rozas, 2009. DnaSP v5: a software for comprehensive analysis of DNA polymorphism data. Bioinformatics 25: 1451-1452.

Montero-Pau, J., A. Gómez, \& J. Muñoz, 2008. Application of an inexpensive and high-throughput genomic DNA extraction method for the molecular ecology of zooplanktonic diapausing eggs. Limnology and Oceanography: Methods 6: 218-222.

Moscatello, S., G. Belmonte, \& G. Mura, 2002. The co-occurrence of Artemia parthenogenetica and Branchinella spinosa (Branchiopoda: Anostraca) in a saline pond of south eastern Italy. Hydrobiologia 486: 201-206.

Muñoz, J., 2009. Implicaciones de la dispersión actual e histórica para la biología evolutiva y conservación de Artemia y otros invertebrados acuáticos con estadio de diapausa. PhD thesis, Spain.

Muñoz, J., F. Amat, A. J. Green, J. Figuerola, \& A. Gómez, 2013. Bird migratory flyways influence the phylogeography of the invasive brine shrimp Artemia franciscana in its native American range. PeerJ PrePrints 1:, https://peerj.com/preprints/79v1.pdf.

Muñoz, J., A. Gómez, J. Figuerola, F. Amat, C. Rico, \& A. J. Green, 2014. Colonization and dispersal patterns of the invasive American brine shrimp Artemia franciscana (Branchiopoda: Anostraca) in the Mediterranean region. Hydrobiologia 726: 25-41. 
Muñoz, J., A. Gómez, A. J. Green, J. Figuerola, F. Amat, \& C. Rico, 2008. Phylogeography and local endemism of the native Mediterranean brine shrimp Artemia salina (Branchiopoda: Anostraca). Molecular Ecology 17: 3160-3177.

Muñoz, J., \& F. Pacios, 2010. Global biodiversity and geographical distribution of diapausing aquatic invertebrates: the case of the cosmopolitan brine shrimp, Artemia (Branchiopoda, Anostraca). Crustaceana 83: 465-20.

Mura, G., A. D. Baxevanis, G. M. Lopez, F. Hontoria, I. Kappas, S. Moscatello, G. Fancello, F. Amat, \& T. J. Abatzopoulos, 2005. The use of a multidisciplinary approach for the characterization of a diploid parthenogenetic Artemia population from Torre Colimena (Apulia, Italy). Journal of plankton research 27: 895-907.

Mura, G., \& B. Brecciaroli, 2004. Use of morphological characters for species separation within the genus Artemia (Crustacea, Branchiopoda). Hydrobiologia 520: 179-183.

Mura, G., I. Kappas, A. D. Baxevanis, S. Moscatello, Q. D’Amico, G. M. Lopez, F. Hontoria, F. Amat, \& T. J. Abatzopoulos, 2006. Morphological and molecular data reveal the presence of the invasive Artemia franciscana in Margherita di Savoia salterns (Italy). International review of hydrobiology 91: 539-554.

Petrović, A., 1991. The karyotype of the parthenogenetic Artemia (Crustacea) from Secovlje, Yugoslavia. Genetica 83: 289-291.

Redón, S., F. Amat, M. I. Sánchez, \& A. J. Green, 2015. Comparing cestode infections and their consequences for host fitness in two sexual branchiopods: alien Artemia franciscana and native A. salina from syntopic-populations. PeerJ 3: e1073.

Reynolds, C., N. A. Miranda, \& G. S. Cumming, 2015. The role of waterbirds in the dispersal of aquatic alien and invasive species. Diversity and Distributions 21: 744-754.

Sánchez, M. I., F. Hortas, J. Figuerola, \& A. J. Green, 2012. Comparing the potential for dispersal via waterbirds of a native and an invasive brine shrimp. Freshwater Biology 57: 1896-1903.

Sánchez, M. I., M. Mata, F. Hortas, \& S. Redón, 2017. El último despertar de Artemia: crónica de una extinción anunciada. Quercus 377: 30-38.

Sánchez, M. I., I. Paredes, M. Lebouvier, \& A. J. Green, 2016. Functional role of native and invasive filter-feeders, and the effect of parasites: learning from hypersaline ecosystems. PloS one 11: $\mathrm{e} 0161478$.

Scalone, R., \& N. Rabet, 2013. Presence of Artemia franciscana (Branchiopoda, Anostraca) in France: morphological, genetic, and biometric evidence. Aquatic Invasions 8: 67-76.

Triantaphyllidis, G., T. Abatzopoulos, \& P. Sorgeloos, 1998. Review of the biogeography of the genus Artemia (Crustacea, Anostraca). Journal of biogeography 25: 213-226.

Van Stappen, G., H. Yu, X. Wang, S. Hoffman, K. Cooreman, P. Bossier, \& P. Sorgeloos, 2007. Occurrence of allochthonous Artemia species in the Bohai Bay area, PR China, as confirmed by RFLP analysis and laboratory culture tests. Fundamental and Applied Limnology/Archiv für Hydrobiologie 170: $21-28$.

Vanhaecke, P., W. Tackaert, \& P. Sorgeloos, 1987. The biogeography of Artemia: an updated review. Artemia research and its applications 1: 129-155. 
Viana, D. S., L. Santamaría, T. C. Michot, \& J. Figuerola, 2013. Migratory strategies of waterbirds shape the continental-scale dispersal of aquatic organisms. Ecography 36: 430-438.

Waterkeyn, A., B. Vanschoenwinkel, S. Elsen, M. Anton-Pardo, P. Grillas, \& L. Brendonck, 2010. Unintentional dispersal of aquatic invertebrates via footwear and motor vehicles in a Mediterranean wetland area. Aquatic Conservation: Marine and Freshwater Ecosystems 20: 580-587. 


\section{Figure captions}

Fig. 1 a Current distribution of Artemia franciscana in the Mediterranean Basin (black), with the new Croatian location (red). b - Native Mediterranean Artemia populations (green) in the vicinity of the easternmost occurrences of Artemia franciscana (based on Abatzopoulos et al., 1987; Vanhaecke et al., 1987; Petrović, 1991; Hontoria \& Amat, 1992; Moscatello et al., 2002; Amat et al., 2005; Mura et al., 2005)

Fig. 2 Statistical parsimony network of Artemia franciscana based on a 548bp COI gene fragment. Haplotypes are labelled according to their original labels from the literature (see Table S1 in Supplementary Material for accession numbers). Black points represent inferred haplotypes not sampled in our dataset. Am. NC: American non-commercial populations; SFB: San Francisco Bay;

GSL: Great Salt Lake; MED: Mediterranean (see Table S1 in Supplementary Material); CRO: Croatia (Nin)

Fig. 3 Eastward spread of Artemia franciscana in the Mediterranean Basin, showing the date of the first record from different locations in seven countries. Locations in France, Spain and Portugal are grouped in three boxes 

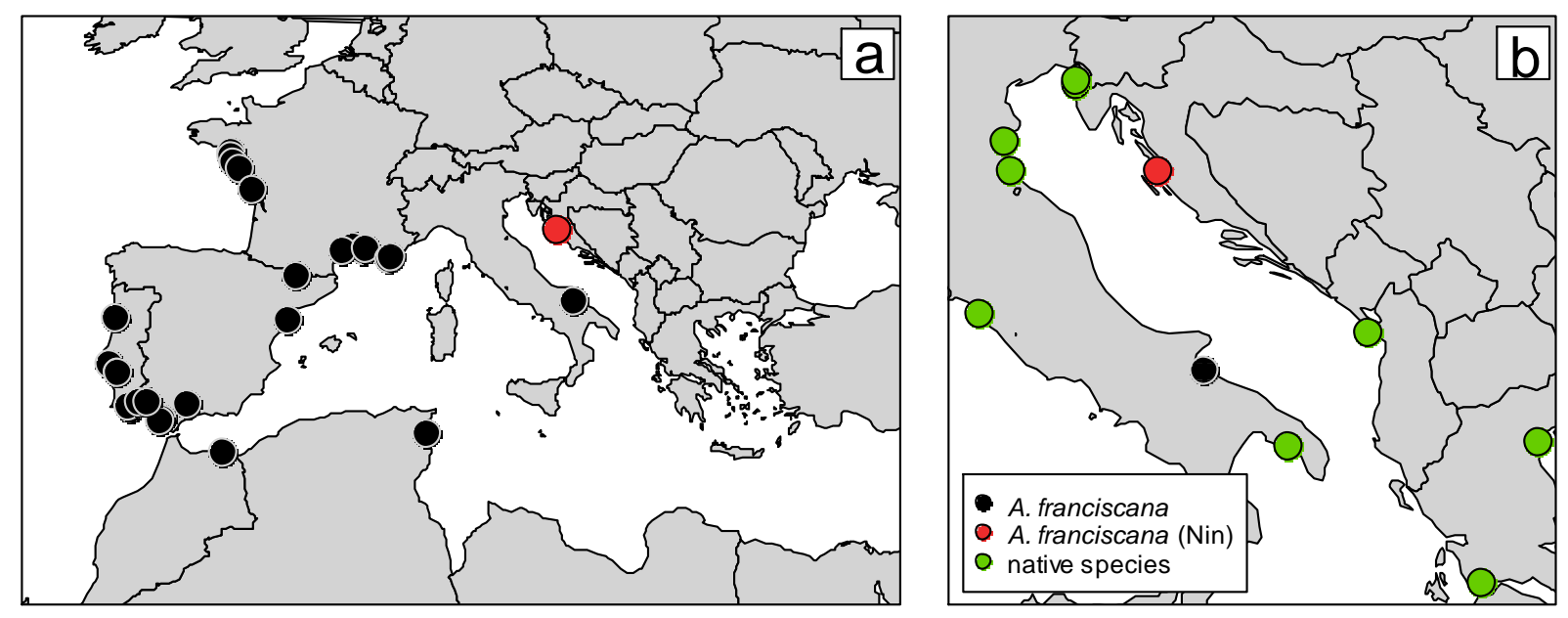


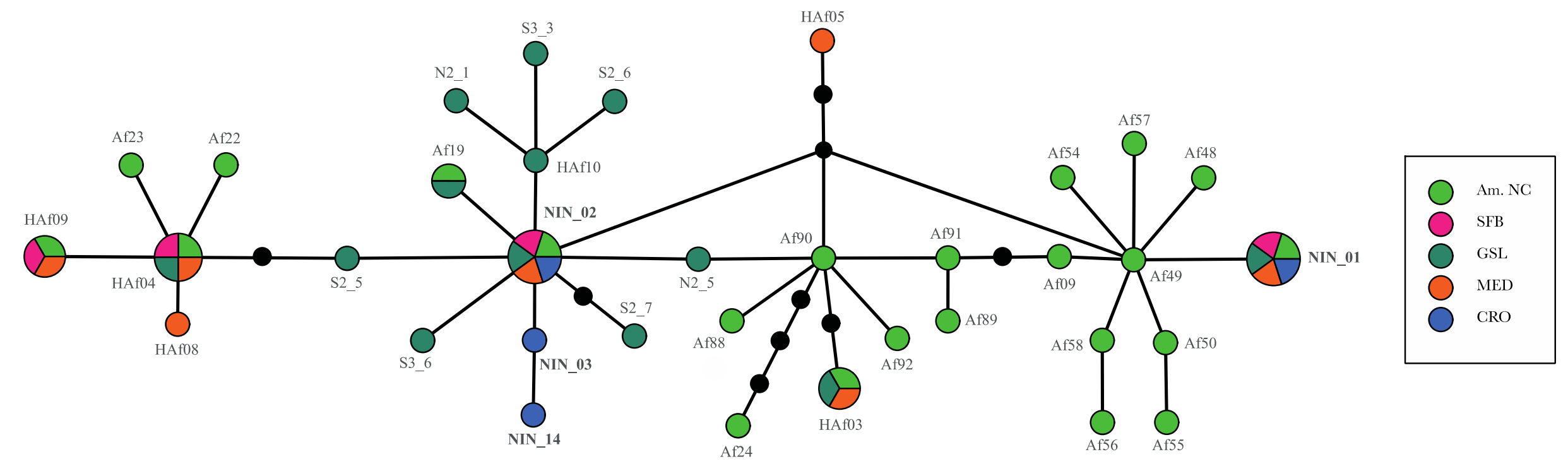




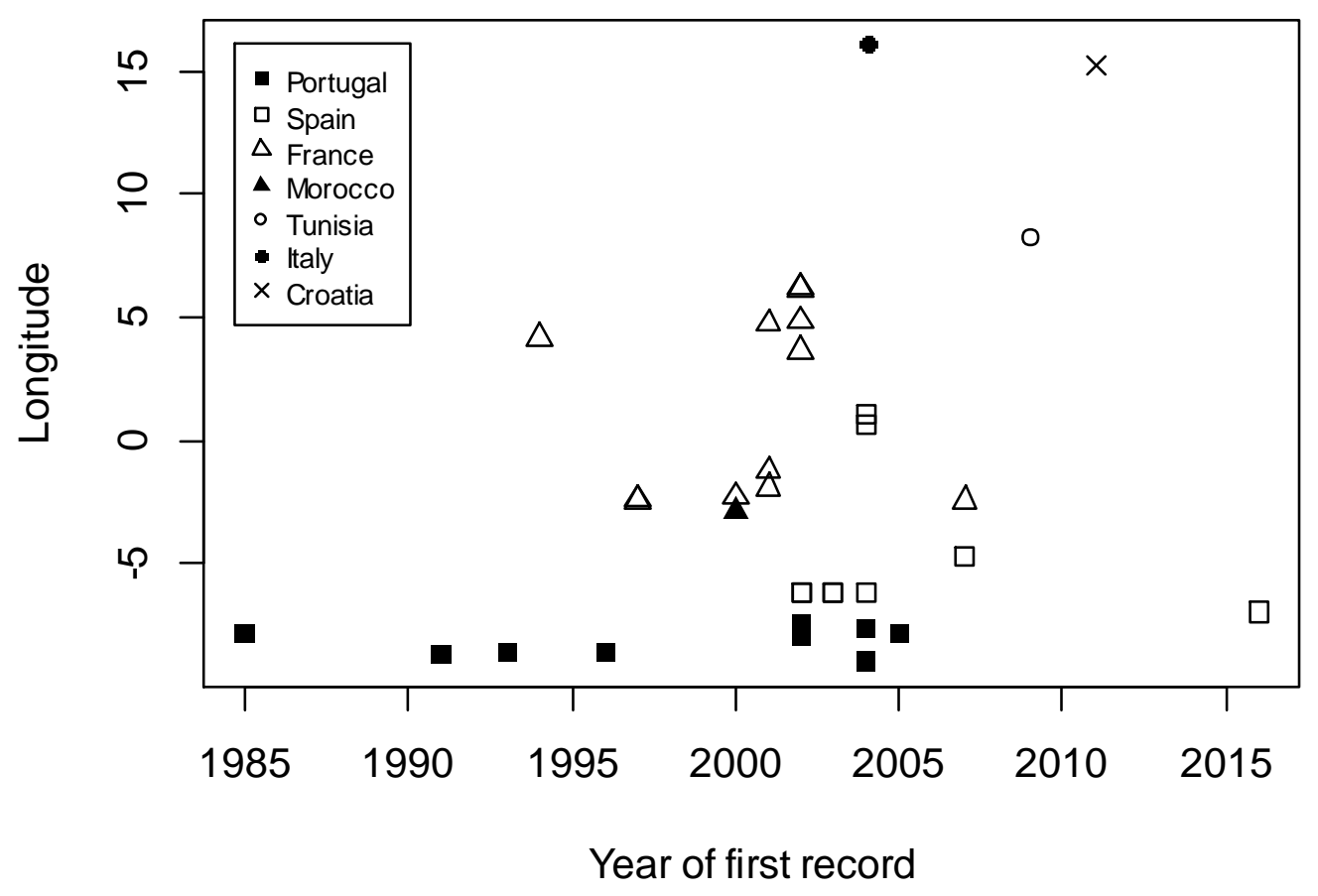

